\title{
Training Model of Innovative Talents in Physical Education Major
}

\author{
$\underline{\text { https://doi.org/10.3991/ijet.v15i24.19035 }}$ \\ Bo Yang \\ Heilongjiang Bayi Agricultural University, Daqing, China \\ yb358666@163. com
}

\begin{abstract}
In the major of physical education (PE), there are several problems with the training model of innovative talents: the model implementation is affected by numerous factors, the training strategies are unclear, and the measurement of the training effect is highly uncertain. To solve these problems, this paper explores deep into the training model of innovative talents in PE major, through both theoretical analysis and calculation modeling. Firstly, the essence of innovative talent training in PE major was summarized, and the training strategies were put forward. On this basis, a measurement model for the training effect was established, based on analytic hierarchy process (AHP) and extenics theory. The research results provide strong supports to the training of innovative talents in PE major.
\end{abstract}

Keywords-Physical education (PE), innovative talent, training model, modern education, extenics theory

\section{Introduction}

At present, with the rapid development of the society, innovative talents have been the driving forces and backbones of national development, and the cultivation of innovative talents has become an important part in the construction of modern human resources [1-4]. The training model of innovative talent is an inevitable trend of modern education development, and a key link in the implementation of quality education. It has an important role in promoting the cultivation of high-level talents [5-8]. As an important part of quality education, PE is an indispensable supplement to the development of modern education. The implementation of an innovative talent training model in PE major will provide great supports for the training of PE professionals, and is conductive to improving the competitiveness of PE talents and developing the physical education [9-11]. Lots of researches on the training model of innovative talent have been conducted. For example, Kwon and Block [12] analyzed the implementation of adaptive E-learning project in PE major. Forey and Cheung [13] studied the benefits of using explicit teaching of PE classroom language in the PE courses. Lin and Pan [14] analyzed the current research status of the training model of innovative talents in PE major and constructed a new training model. Tang [15] conducted research on the current research status of the training model of innovative talents in 
PE majors, and explored the means for the implementation of this model. Liu [16] discussed the logical relationship and the corresponding realization path of the innovative talents training in PE major in the context of "Internet + ". The research above is of great significance to positively guiding the training of innovative talents and implementing the related training model in PE major. However, it is very challenging to implement the said model, and there is still a broad research space in terms of key research content. For this reason, this paper summarizes the existing research results, and deeply studies the training model of innovative talents in PE major through the theory analysis and calculation modelling based on AHP [17-18] and extenics theory [19-20].

This study consists of six parts. Part 1 summarizes the related research content of modern education and innovative talent training; Part 2 discusses the inner relationship between the training model of innovative talents in PE major and Physical education development; Part 3 analyzes the constraints on the development of innovative talents training model in PE major; Part 4 explores the implementation path and strategies; Part 5 constructs an index system for the training effect analysis of the training model, and establishes the corresponding measurement model; the last part gives the research conclusion.

\section{The Inner Relationship between the Training Model of Innovative Talents in PE Majors and the Development of Physical Education}

Talents are strategic resources for the development of modern society. The training of high-level talents is an important means to promote social development and national progress. Innovative talents are the cores of talent resources and important symbols of enhancing the social competitiveness. From the perspective of modern education, innovative talents in PE major, as the backbones of physical education, play a key role in improving the level of physical education development and the overall PE quality. Therefore, the development of physical education should focus on the training of innovative talents in PE major, while the training of innovative talents needs to be carried out according to the development needs of physical education. Both show an inner relationship of mutual coordination, promotion, and reinforcement.

\subsection{The training model of PE innovative talents is the inevitable trend in the development of physical education}

The traditional training model of PE major focuses on the training of applied professionals. Such model is exam-oriented in the training of PE professionals. Thus, the trained PE professionals obtain certain theoretical knowledge, but lack necessary practicality, and their comprehensive quality and innovation ability are poor. Following the continuous improvement of the modern society and modern education technology, the current talent training model in higher education has been gradually difficult to meet the needs of social development, and to achieve the goals and plans 
of modern education development; also the social demand of high-level talent has been more pressing, and the cultivation of high-level innovative talents has gradually become the mainstream form of modern education development. The training of innovative talents in the PE major can ensure to provide professional talents with strong innovation ability and comprehensive quality, and further promotes the development of physical education, while the development of physical education also requires the talent resource guaranteed by the training model of innovative talents.

\subsection{The training model of PE innovative talents meets the demand of PE teaching reform}

Due to the continuous development of modern education technology, modern physical education is gradually changing from traditional test-oriented to quality-oriented education. But considering the influence of numerous factors in the traditional physical education process, modern model is difficult to form quickly and effectively. Also, in the changing process, many unknown problems will inevitably appear. If these problems cannot be analyzed and dealt with scientifically and reasonably, it must hinder the development of modern physical education. Innovation and reform are the driving forces for modern education. To develop the modern physical education, the most effective way is to carry out effective teaching reform, which can solve various problems in the existing physical education process, deal with the negative influencing factors, and break the existing educational shackles, thereby providing effective solutions to the development of physical education. Therefore, from the perspective of innovation and reform, the implementation of the innovative talent training model in PE major is an urgent need for modern physical education reform, which will enhance the reform ability of modern physical education.

\subsection{The training model of PE innovative talents is the guarantee condition for improving the PE teaching quality}

Apparently, the training model of innovative talents in PE majors differs from the tradition model only in terms of training form. It has no significant impact on the PE teaching quality, and causes no many changes in the development of physical education. However, this is not essentially true. From the form, this model is a change from the traditional PE professional talent training model, but the former pays more attention to the professional knowledge, innovation ability, learning ability, and thinking and resolving ability of PE professionals, and it is more conducive to the output of high-level and high-quality sports professionals. From the internal relations, it is a comprehensive improvement of modern physical education in terms of teaching philosophy, teaching methods, teaching means, teaching forms, teaching content, teaching management systems, and teaching assessments etc. The complete implantation of this model in different aspects will provide a solid guarantee for the improvement of PE teaching quality. 


\subsection{The development of physical education promotes and expands the training model of innovative talents in PE major}

From the above, the implementation of the training model for PE innovative talents is an inevitable trend in the current development of physical education, and an important part of the physical education teaching reform. It can provide not only a strong support for the training of high-level PE professionals, but also a solid guarantee for the improvement of PE teaching quality. With the development of modern physical education and the continuous outputs of high-level PE professionals, higher requirements are put forward for the implementation of the said training model and cultivation of PE innovative talents. For this, it's necessary to solve the key issues more fully in the implementation of the training model under the new situation, continuously expand the scope of the training model for innovative talents, deepen the intrinsic nature of the training model, and further improve its implementation effect. This kind of virtuous circle will further strengthen the inner relationship of mutual coordination, promotion and support between the training model of PE innovative talents and the development of physical education.

\section{Constraints on the Development of Innovative Talent Training Models for PE Majors}

In view of the mutually reinforcing between the training model of PE innovative talents and the development of physical education, it's of great significance to develop the training model for cultivating high-level professional talents in PE major. However, due to many shortcomings in the current physical education environment, the implementation of this model is still constrained by many factors as follows.

\subsection{The lack of innovative educational concepts}

The training model for innovative talents in PE major requires corresponding teaching management systems and educators. The teaching management system must be able to effectively reflect the training goals, planning, tasks, management, and assessment, and manifest the inherent nature of the training model, so as to provide directional guidance for the establishment of correct innovative education concepts in PE major. At the same time, the educators, as the main carriers for implementing the innovative talent training model, have the most direct impact on the implementation process of the said model. The teaching concept of the educators should keep up with the current development requirements of the physical education, because it directly determines the implementation effect of the model. Nevertheless, in the transforming process from a traditional education model to an innovative education model in PE major, there still remains many factors of the traditional model, and the innovative education concept of the PE major needs to be further improved. 


\subsection{Weak faculty in the training of PE innovative talents}

The continuous development of modern education technology and quality-oriented education has further highlighted the role of PE teaching in modern education, and encouraged the colleges to invest more in human resources of physical education. However, compared with other majors, the faculty in PE major is relatively weak, and especially in the process of promoting the training model of innovative talents, high-level professional teachers are relatively lacking. In addition, there is also a lack of abilities to build a professional team with a good talent echelon structure, which on the one hand cannot guarantee the effective introduction of high-level, highly-educated and high-title professionals, and on the other hand, fails to effectively develop and utilize internal talents, even leading to the loss of internal professional talents. This shall greatly affect the faculty of innovative education, failing to provide effective support for the implementation of the training model.

\subsection{Insufficient input resources of basic education in PE major}

The PE major is relatively weak compared to other disciplines or majors such as science, engineering, medicine, agronomy, and management engineering. It often receives a small proportion of basic education resources invested by schools, which makes it difficult to effectively guarantee the development of physical education, while the training of innovative talents in PE major requires much investment in basic education resources. Although with the development of modern society, the school's investment of basic education resources in the construction of physical education has been improved to a certain extent than before, it is often reflected in the hardware facilities such as construction of physical education site venues, stadium, and equipment. These hardware facilities are just face projects and cannot be effectively applied to the PE teaching process. Meanwhile, the supporting software facilities are lacking, so that the inputs of basic education resources in PE cannot give full play, and fail to promote the effective training of PE innovative talents.

\subsection{Incomplete training system for PE innovative talents}

The management of PE education means not only to coordinate the relationship between human resources, financial resources, and material resources, but also to reflect the goal, planning and social nature of the PE talent training. As the training model of innovative talent in PE is implemented constantly and deeply, the related talent training system has not been improved simultaneously. Especially some detail problems in the implementation process of the training model are difficult to be solved effectively, and there still exist some deficiencies in the links such as teaching task planning, teaching work management, teaching performance management, teaching incentive mechanism, and student management, etc. Therefore, it's urgent to keep the training system in line with the implementation of the training model, and effectively meet the needs of social development. Only a perfect training system for 
innovative talents in PE major can better promote the implementation of this training model.

\subsection{Low reform and innovation ability in PE major}

The training model of innovative talents in PE major is an innovation of the existing training models. It's implemented through the PE teaching reform. This model needs to be completed through the joint efforts of educators in different links of the $\mathrm{PE}$ teaching. In this process, it is necessary for educators to brainstorm, take more responsibility for teaching reform topics, and study the essentials of the cultivation of innovative talent training. Especially the effective reforms and innovations should be conducted in terms of teaching concepts, teaching methods, teaching means, teaching forms, teaching content, and teaching management system, and teaching assessment mechanism, etc., and supporting measures, strategies and ways are proposed. This shall provide impetus for the implementation of the model. But there are still some shortcomings in the reform and innovation of the current PE teaching reform. On the one hand, there is a lack of an environment for the teaching reform and innovation; on the other hand, the teaching reform and innovation of the PE major are often mere formalities, which cannot effectively improve the teaching reform and innovation ability of PE major, nor can it provide sufficient support for the implementation of the training model.

\subsection{The disconnection between the talent training program of PE major and social needs}

The continuous social development has posed more urgent requirements for talents, i.e., talent training has certain professional and social attributes. The training of innovative talents characterizes the social demands for innovative talents and especially innovative abilities. From this perspective, the integration in two aspects should be highlighted in the training of PE innovative talents: One is the integration of theoretical knowledge and social practice, so that the theoretical knowledge and professional practice must be organically combined; the other is the integration of major settings and social needs; the purpose of talent training is to better serve the society, and then the training of innovative talents in PE majors must meet the development needs of the society. However, according to the actual implementation of the current innovative talent training model, there are still problems in the social practice and social needs. This is because more emphasis is placed on theoretical learning, lacking necessary practice, which may lead to certain restrictions on the scope of PE talents' innovative ability, and influence the training effect of innovative talents. 


\section{Strategies for Implementing the Training Model of Innovative Talents in PE Major}

To effectively improve the implementation effect of the training model for innovative talents in PE majors, the authors proposed some strategies from the following aspects.

\subsection{Increasing investment in the infrastructure construction of the PE major}

The training model of innovative talent in PE major should be implemented under the support of software and hardware facilities. This is also the basic guarantee for the in-depth development of the training model. Therefore, it's critical to increase the investment in the PE infrastructure. In the process of implementing the said training model, the investment in the infrastructure construction of the PE major needs to focus on three aspects: one is whether the investment in the infrastructure construction is consistent with the training goal and professional construction planning of the PE major; the second is whether the investment meets the needs of the training of innovative talents; the third is whether the investment is sustainable and competitive for the implementation of the training model.

\subsection{Enhancing the innovative teaching concept in PE major}

The change in teaching concept is the key factor for the transformation of teaching model, and the advancement of the teaching concept seriously affects the training effect. Thus, in the process of implementing the training model of innovative talents in PE major, it's necessary for the educators to first change the PE teaching thinking and form an innovative teaching concept with modern education characteristics. The authors proposed to educate, study and train PE professional educators through various methods, constantly contact modern educational concepts and educational techniques, and verify and analyze them in the PE practice process, thereby enabling the educators to have a deeper understanding of the innovative talent training model.

\subsection{Enhancing the ability of the faculty team for training PE innovative talents}

The faculty team is the backbone for the implementation of the innovative talent training model in PE major, and it's also the key carrier to manage the training effect. So, it's the prerequisite for the effective implementation of the training model to enhance the ability of the faculty team. The authors proposed to enhance the ability of faculty team for training of PE innovative talents in three aspects. First, improve the comprehensive professional quality of PE teachers, and ensure them to have solid professional knowledge. Second, optimize the talent structure of the faculty team, and do a good job in the introduction and training of high-level professional teachers. Third, promote the communication and learning ability of the PE teachers, and ensure 
the good sustainability and competitiveness of the faculty team in the training of innovative talents for PE majors.

\subsection{Improving the reform and innovation ability of PE teachers according to the development needs of the times}

As the development of modern society accelerates continuously, the society's demand for high-level innovative talents in PE becomes much more pressing. Also, social development, as a dynamic process, causes lots of uncertainty and makes the training of PE innovative talents a complex system process in the cultivation of PE innovative talents. Thus, it's urgently needed to conduct the educational reform and innovation. The authors proposed to improve the reform and innovation ability of the PE teachers in the training of PE innovative talents in three aspects. First, it is necessary to strengthen the teaching reform and innovation awareness of PE teachers according to the time characteristics and needs of the current social development, and formulate teaching reform and innovation guidelines with clear goals; second, encourage the PE teachers to actively undertake or participate in teaching reform and innovation projects during the implementation of the innovative talent training model, and perform in-depth study of the essential issue; third, summarize and analyze the results of the physical education reform, and effectively apply them to the follow-up teaching, thereby improving the reform and innovation ability of the teachers in practice.

\subsection{Making a sound training program of innovative talents, and improving the management system}

In order to make a sound training program of innovative talents in PE major, the PE educators need to formulate scientific and reasonable talent training goals according to the requirements of PE professional development, and corresponding implementation plans, which provides a direction for implementing the training model. For this, a sound management system is required. The authors proposed to improve the management system in the four aspects as follows. First, build a good management system of PE innovative talent training resource to optimize human resources, financial resources and material resources; second, form a sound teaching management system for the training of innovative talents to achieve effective management of physical education; third, establish a good student management system for the training of innovative talents to effectively supervise the learning process of students; fourth, form a proper teaching and learning incentive mechanism, and implement the integration of multiple incentive mechanisms, thereby enhancing the teaching and learning capabilities in the cultivation of innovative talents. 


\subsection{Reinforcing the industry-university-research cooperation in the innovative talent training of PE majors}

The industry-university-research cooperation in the training process of $\mathrm{PE}$ innovative talents is to combine the cultivation of innovative talents with the social sports industry and sports science research, improve the theoretical understanding and practical verification of PE teaching, and then promote the teaching quality for innovative talents in PE, thus cultivating more high-level PE professionals. The highlevel professional talents trained can be quickly engaged in the development of the sports industry and scientific research, which can further deepen the development of the sports industry and scientific research results. Therefore, in order to improve the effect of training innovative talents in PE, it is necessary to enhance the integration of industry, university, and research in the training process. First, build a set of effective industry-university-research cooperation mechanism according to the actual situation of the training model for PE innovative talents; second, well plan the content of industry-university-research integration, reasonably set their respective proportion and task planning, and take effective measures; third, establish a good evaluation mechanism for the effect of industry-university-research integration in the training mode, achieve effective evaluation, and be able to improve the weak links according to teaching goals.

\section{Analysis for the Implementation Effect of the Training Model of Innovative Talents in PE Major}

To measure the effectiveness of the training model for PE innovative talents, it is necessary to conduct an effective analysis for the implementation effects of this model.

\subsection{Constructing an index system for the implementation effect measurement}

Based on survey analysis, summarization of relevant research results, and consulting research scholars in related fields, the authors constructed the evaluation index system for the implementation effects of the said training model from different aspects such as teaching skills, student professional technical ability training, student innovation ability training, student independent learning ability training, student social practice ability training, and the reflection of teaching and learning effects etc. Table 1 lists the specific content and hierarchical structure. 
Table 1. The index system for implementation effect measurement

\begin{tabular}{|c|c|c|}
\hline Index system & Primary indicators & Secondary indicators \\
\hline \multirow{40}{*}{$\begin{array}{l}\text { The evaluation index system } \\
\text { for the implementation } \\
\text { effects of the training model } \\
\text { of innovative talents in PE } \\
\text { major }\end{array}$} & \multirow{8}{*}{ Teaching skill } & Teachers' professional quality and level \\
\hline & & Perfection of teaching system \\
\hline & & Basic guarantee conditions for teaching \\
\hline & & Advancement of teaching concept \\
\hline & & Scientific nature of teaching methods \\
\hline & & Intelligence of teaching means \\
\hline & & Epochal Character of teaching content \\
\hline & & Variety of teaching forms \\
\hline & \multirow{6}{*}{$\begin{array}{l}\text { Student professional technical } \\
\text { ability training }\end{array}$} & Professional knowledge reserve \\
\hline & & Technical mastery \\
\hline & & Coordination \\
\hline & & Observation \\
\hline & & Responsiveness \\
\hline & & Teamwork \\
\hline & \multirow{4}{*}{$\begin{array}{l}\text { Student innovation ability } \\
\text { training }\end{array}$} & Ability to find problems \\
\hline & & Ability to extract problems \\
\hline & & Ability to solve problems independently \\
\hline & & Ability of expansive analysis \\
\hline & \multirow{4}{*}{$\begin{array}{l}\text { Student independent learning } \\
\text { ability training }\end{array}$} & Pre-class preparation ability \\
\hline & & $\begin{array}{l}\text { Classroom interaction and communication } \\
\text { skills }\end{array}$ \\
\hline & & After-class summary and feedback ability \\
\hline & & Learning development ability \\
\hline & \multirow{3}{*}{$\begin{array}{l}\text { Student social practice ability } \\
\text { training }\end{array}$} & Ability to integrate theory and practice \\
\hline & & $\begin{array}{l}\text { Industry-university-research integration } \\
\text { capability }\end{array}$ \\
\hline & & Learning transformation ability \\
\hline & \multirow{15}{*}{$\begin{array}{l}\text { The reflection of teaching and } \\
\text { learning effects }\end{array}$} & Number of teaching reform projects \\
\hline & & Number of teaching awards \\
\hline & & Number of high-level teaching papers \\
\hline & & Number of transformed teaching results \\
\hline & & Student pass rate \\
\hline & & Student excellence rate \\
\hline & & Student turnover rate \\
\hline & & Employment rate of students \\
\hline & & Entrepreneurship ratio of students \\
\hline & & Student's entrepreneurial success rate \\
\hline & & $\begin{array}{l}\text { Number of students participating in social } \\
\text { practice }\end{array}$ \\
\hline & & Number of student awards \\
\hline & & Social satisfaction \\
\hline & & Student satisfaction \\
\hline & & Completeness of training goals \\
\hline
\end{tabular}




\subsection{Processing and analyzing evaluation indicators of implementation effect}

In the index system above, different evaluation indicators for the implementation effect analysis of the innovative talent training models may vary in terms of physical dimensions. They need to be normalized in order to reduce their impact on the measurement results. It's assumed that the value of the $\mathrm{j}$-th indicator for the $\mathrm{i}$-th analysis object is $V_{i j}=\left[v_{i j}(l e f), v_{i j}(r i g)\right], v_{i j}(l e f) \leq v_{i j}(r i g), 1 \leq \mathrm{i} \leq \mathrm{m}, 1 \leq \mathrm{j} \leq \mathrm{n}$, and the value range of the j-th indicator is $V_{j}^{t h r}=\left[v_{j}^{t h r}(l e f), v_{j}^{t h r}(r i g)\right]$.

If the $\mathrm{j}$-th indicator is a benefit index, its normalized value Rij is given as:

$$
R_{i j}=\left[r_{i j}(l e f), r_{i j}(r i g)\right]=\left[\frac{v_{i j}(l e f)-v_{j}^{t h r}(l e f)}{v_{j}^{t h r}(r i g)-v_{j}^{t h r}(l e f)}, \frac{v_{i j}(r i g)-v_{j}^{t h r}(l e f)}{v_{j}^{t h r}(r i g)-v_{j}^{t h r}(l e f)}\right]
$$

If it's a cost index, its normalized value Rij is given as:

$$
R_{i j}=\left[r_{i j}(l e f), r_{i j}(r i g)\right]=\left[\frac{v_{j}^{t h r}(r i g)-v_{i j}(r i g)}{v_{j}^{t h r}(r i g)-v_{j}^{t h r}(l e f)}, \frac{v_{j}^{t h r}(r i g)-v_{j}^{t h r}(l e f)}{v_{j}^{t h r}(r i g)-v_{j}^{t h r}(l e f)}\right]
$$

Similarly, different evaluation indicators o may vary in terms of the importance. For this, the AHP method [21-22] was used to obtain the weights of the corresponding indicators.

First, consult experts in the field, evaluate the indicators using the 1-9 score scale, and then obtain the judgment matrix $\mathrm{A}$ of the indicator weights for measuring the implementation effect of PE innovative talent training model.

$$
\boldsymbol{A}=\left[a_{i j}\right]_{n x n}
$$

And aij represents the importance of the $\mathrm{i}$-th indicator compared to the $\mathrm{j}$-th indicator, aij=1/aji.

Then, normalize the judgment matrix A to obtain the weight wj of the $j$-th indicator,

$$
w_{i}=\sqrt[n]{\prod_{j=1}^{n} b_{i j}} / \sum_{i=1}^{n} \sqrt[n]{\prod_{j=1}^{n} b_{i j}}
$$

Next, perform the consistency test of the judgment matrix, namely

$$
\left\{\begin{array}{l}
C I=\frac{\lambda_{\max }(A)-n}{n-1} \\
C R=C I / R I
\end{array}\right.
$$

where, $\lambda \max (\mathrm{A})$ is the largest eigenvalue of the judgment matrix, RI is the random consistency index, and its value is selected based on the number $\mathrm{n}$ of evaluation indicators. 
If $\mathrm{CR}<0.1$, it indicates that the weights of the indicators is reasonably allocated, otherwise it needs to be reprocessed.

\subsection{Classical domain division}

The classical domain for the implementation effect analysis of the training model of innovative talents in PE major is related to the levels of its implementation effect. For different levels of the implementation effect, the value ranges of the analysis indicators also vary. Assuming that the implementation effect of the PE innovative talent training model is classified into $\mathrm{K}$ levels, then the classical domain of the $\mathrm{j}$-th indicator at the level $\mathrm{k}$ of implementation effect is $U_{j}^{k}=\left[u_{j}^{k}(l e f), u_{j}^{k}(r i g)\right]$, $u_{j}^{k}($ lef $) \leq u_{j}^{k}(r i g)$, and $1 \leq \mathrm{k} \leq \mathrm{K}$.

Similar to the normalization processing above, the value of the classical domain $U_{j}^{k}$ was obtained on the basis of the normalized value, so the value range was in the closed interval of 0 -1, i.e., $0 \leq u_{j}^{k}($ lef $) \leq u_{j}^{k}($ rig $) \leq 1$. The implementation effect level of the training model can be classified in terms of different accuracy of implementation effect, that is, give the relevant setting based on the form of $0-1$ for poorexcellent. Under normal circumstances, it is not advisable to divide the implementation effect too much or too little, both of which will affect the final analysis accuracy and discrimination ability.

\subsection{Extenics -based measurement model for implementation effect}

After obtaining the classical domain $U_{j}^{k}$, the joint domain $U_{j}^{*}$ of the $\mathrm{j}$-th indicator can be constructed,

$$
U_{j}^{*}=\left[u_{j}^{*}(\text { lef }), u_{j}^{*}(\text { rig })\right]=\left[\min _{1 \leq k \leq K} u_{j}^{k}(\text { lef }), \max _{1 \leq k \leq K} u_{j}^{k}(\text { rig })\right]
$$

Based on the extenics theory [23-25], the extension distance $\rho_{i j}^{k}\left(R_{i j}\right)$ between the $\mathrm{j}$-th indicator and the classical domain $U_{j}^{k}$ of the ${ }^{i}$-th analysis object is given as:

$$
\rho_{i j}^{k}\left(R_{i j}\right)=\left|R_{i j}-\frac{u_{j}^{k}(\text { rig })+u_{j}^{k}(\text { lef })}{2}\right|-\frac{u_{j}^{k}(\text { rig })-u_{j}^{k}(\text { lef })}{2}
$$

Similarly, the extension distance $\rho_{i j}^{*}\left(R_{i j}\right)$ between the $\mathrm{j}$-th indicator and the joint domain $U_{j}^{*}$ of the ${ }^{i}$-th analysis object is given as:

$$
\rho_{i j}^{*}\left(R_{i j}\right)=\left|R_{i j}-\frac{u_{j}^{*}(\text { rig })+u_{j}^{*}(l e f)}{2}\right|-\frac{u_{j}^{*}(r i g)-u_{j}^{*}(l e f)}{2}
$$

In particular, at $R_{i j}=\left[r_{i j}(l e f), r_{i j}(r i g)\right]$, the extension distance $\rho_{i j}^{k}\left(R_{i j}\right)$ can be expressed as: 


$$
\begin{aligned}
& \rho_{i j}^{k}\left(R_{i j}\right)=\frac{1}{2}\left(\rho_{i j}^{k}\left(r_{i j}(l e f)\right)+\rho_{i j}^{k}\left(r_{i j}(r i g)\right)\right) \\
& =\frac{\left|r_{i j}(l e f)-\frac{u_{j}^{k}(r i g)+u_{j}^{k}(l e f)}{2}\right|+\left|r_{i j}(r i g)-\frac{u_{j}^{k}(r i g)+u_{j}^{k}(l e f)}{2}\right|-\left(u_{j}^{k}(r i g)-u_{j}^{k}(l e f)\right)}{2}
\end{aligned}
$$

Similarly, the extension distance $\rho_{i j}^{*}\left(R_{i j}\right)$ can also be expressed as:

$$
\begin{aligned}
& \rho_{i j}^{*}\left(R_{i j}\right)=\frac{1}{2}\left(\rho_{i j}^{*}\left(r_{i j}(l e f)\right)+\rho_{i j}^{*}\left(r_{i j}(\text { rig })\right)\right) \\
& =\frac{\left|r_{i j}(l e f)-\frac{u_{j}^{*}(r i g)+u_{j}^{*}(l e f) \mid}{2}\right|+\left|r_{i j}(r i g)-\frac{u_{j}^{*}(r i g)+u_{j}^{*}(l e f)}{2}\right|-\left(u_{j}^{*}(r i g)-u_{j}^{*}(l e f)\right)}{2}
\end{aligned}
$$

Then, the extension correlation coefficient $\phi_{i j}^{k}\left(R_{i j}\right)$ between the $\mathrm{j}$-th indicator and the classical domain $U_{j}^{k}$ of the i-th analysis object can be obtained as:

$$
\phi_{i j}^{k}\left(R_{i j}\right)= \begin{cases}-\rho_{i j}^{k}\left(R_{i j}\right) /\left|U_{j i j}^{k}\right| & R_{i j} \in U_{j}^{k} \\ \rho_{i j}^{k}\left(R_{i j}\right) /\left(\rho_{i j}^{*}\left(R_{i j}\right)-\rho_{i j}^{k}\left(R_{i j}\right)\right) & R_{i j} \notin U_{j}^{k}\end{cases}
$$

Combining the obtained weight wj of the $\mathrm{j}$-th indicator, the extension superiority $\psi_{i}^{k}$ between the i-th analysis object and the implementation effect level k can be derived as:

$$
\psi_{i}^{k}=\sum_{j=1}^{n}\left(w_{j} * \phi_{i j}^{k}\left(R_{i j}\right)\right)
$$

Obviously, the larger extension superiority indicates a higher probability that the ith analysis object belongs to the implementation effect level $\mathrm{k}$.

\section{Conclusion}

This paper attempts to explore the training model of innovative talents in PE major. To this end, it performs an in-depth study of the inner relationship between the said training model and the physical education development, the constraints on the development of the model, and its implementation etc. Then, an improved index system and extenics-based measurement model were established to effectively measure the implementation effect of the innovative talent training model. This study provides a guiding role for the effective implementation of the training model of innovative talents in PE majors. 


\section{$7 \quad$ References}

[1] Azevedo, A., Shane, M.J. (2019). A new training program in developing cultural intelligence can also improve innovative work behavior and resilience: A longitudinal pilot study of graduate students and professional employees. The International Journal of Management Education, 17(3): 100303. https://doi.org/10.1016/j.ijme.2019.05.004.

[2] Li, H.L. (2020). Reflections on the Reform of Undergraduate Education Driven by Project System. Journal of Soochow University (Educational Science Edition), 2020(3): 55-64. http://dx.doi.org/10.19563/J.cnki.sdjk.2020.03.007.

[3] Jahnke, I., Liebscher, J. (2020). Three types of integrated course designs for using mobile technologies to support creativity in higher education. Computers \& Education, 146: 103782. https://doi.org/10.1016/j.compedu.2019.103782.

[4] Aichouni, M., Touahmia, M., Al-Ghamdi, A., Ait-Messaoudene, N., Al-Hamali, R. M., AlGhonamy, A., \& Al-Badawi, E. (2015). Creativity and innovation among gifted saudi students-an empirical study. Procedia-Social and Behavioral Sciences, 195: 1371-1379. https ://doi.org/ 10.1016/j.sbspro.2015.06.403.

[5] Wang, X.T., Fan, X.C. (2020). Training Model of Interdisciplinary Innovative Talents Based on Maker Education. Journal of Shenzhen Polytechnics, 19(4): 81-83. https://doi. org/10.13899/j.cnki.szptxb.2020.04.014.

[6] Erman, K.A., Şahan, A., Balci, Y.K. (2015). The vocational maturity of school of physical education and sports students. Procedia-Social and Behavioral Sciences, 174: 2380-2383. https://doi.org/ 10.1016/j.sbspro.2015.01.904.

[7] Kuo, H.C., Tseng, Y.C., Yang, Y.T.C. (2019). Promoting college student's learning motivation and creativity through a STEM interdisciplinary PBL human-computer interaction system design and development course. Thinking Skills and Creativity, 31: 1-10. https:// doi.org/10.1016/j.tsc.2018.09.001.

[8] Dong, X.C. (2015). Research on the Sports Culture Construction in College and Universities Based on the Cultivation of Innovative Talents. Journal of Jilin Sport University, 2015(6): 13. https://doi.org/10.13720/j.cnki.22-1286.2015.06.013.

[9] Ren, B. (2018). Research on College Physical Education Teaching Reform of cultivating innovative talents under the concept of Internet. Contemporary Sports Technology, 2018, 8(9): 72-73. https://doi.org/10.16655/i.cnki.2095-2813.2018.09.072.

[10] Guo, T.L. (2018). Research on the relationship between the cultivation of innovative talents and the reform of physical education in Colleges and Universities under the Internet mode. Contemporary Sports Technology, 8(9): 74-75. https://doi.org/10.16655/j.cnki.20 95-2813.2018.09.074.

[11] Xiao, T. (2016). Research on the construction of innovative talents training mode of Aerobics in Physical Education Major. Contemporary Sports Technology, 6(27): 48-49. https:// doi.org/10.16655/j.cnki.2095-2813.2016.27.048.

[12] Kwon, E.H., Block, M.E. (2017). Implementing the adapted physical education E-learning program into physical education teacher education program. Research in developmental disabilities, 69: 18-29. http://dx.doi.org/10.1016/j.ridd.2017.07.001.6.

[13] Forey, G., Cheung, L.M.E. (2019). The benefits of explicit teaching of language for curriculum learning in the physical education classroom. English for Specific Purposes, 54: 91-109. https://doi.org/10.1016/j.esp.2019.01.001.

[14] Lin, Y., Pan, S.K. (2019). Research on the training mode of innovative talents in Physical Education. Journal of Tonghua Normal Uninversity, 40(6): 111-114. https://doi.org/10.138 77/j.cnki.cn22-1284.2019.12.025.

[15] Tang, J.C. (2019). Research and Practice on the Training Model of Innovative Talents in PE Majors in General Colleges and Universities. Sport Science and Technology, 40(4): 125-126. https://doi.org/10.14038/j.cnki.tykj.2019.04.058. 
[16] Liu, C.M. (2018). "Internet +": Logical Analysis and Realization Path of Driving Chinese School Physical Education to Cultivate Innovative Talents. Journal of Anhui Normal University (Natural Science), 41(6): 604-608. https://doi.org/10.14182/J.cnki.1001-2443.2018. $\underline{06.016}$.

[17] Yang, Z.H. (2020). Analysis of the impacts of open residential communities on road traffic based on AHP and fuzzy theory. Ingénierie des Systèmes d'Information, 25(2): 183-190. https://doi.org/10.18280/isi.250205

[18] Barić, D., Pižeta, F. (2018). An AHP model for level crossing design. International Journal of Safety and Security Engineering, 8(1): 65-76. https://doi.org/10.2495/SAFE-V8-N1-6576

[19] Guo, Q., Zou, G.T., Sun, T.Z. (2018). Discovery of the knowledge on the demands of building users based on extension clustering. Revue d'Intelligence Artificielle, 32(5-6): 705-718. https://doi.org/10.3166/ria.32.705-718

[20] Dong B.K., Zhu X.N., Yan R., Zhang C.L. (2019). Evaluation of third-party reverse logistics providers based on extension superiority method, Ingenierie des Systemes d'Information, 24(1): 101-105. https://doi.org/10.18280/isi.240115

[21] Akbulut, A., Ozcevik, O., Carton, L. (2018). Evaluating suitability of a GIS-AHP combined method for sustainable urban and environmental planning in Beykoz district, Istanbul. International Journal of Sustainable Development and Planning, 13(8): 1103-1115. https://doi.org/10.2495/SDP-V13-N8-1103-1115

[22] Wang, W.X. (2019). Site selection of fire stations in cities based on geographic information system (GIS) and fuzzy analytic hierarchy process (FAHP). Ingénierie des Systèmes d'Information, 24(6): 619-626. https://doi.org/10.18280/isi.240609

[23] Ren, J., Manzardo, A., Toniolo, S., Scipioni, A. (2013). Sustainability of hydrogen supply chain. Part II: Prioritizing and classifying the sustainability of hydrogen supply chains based on the combination of extension theory and AHP. International journal of hydrogen energy, 38(32): 13845-13855. http://dx.doi.org/10.1016/j.ijhydene.2013.08.078.

[24] Seng, D.W., Zhang, H.Q., Fang, XJ., Zhang, X.F., Chen, J. (2018). An improved fingerprint image matching and multi-view fingerprint recognition algorithm. Traitement du Signal, 35(3-4): 341-354. https://doi.org/ 10.3166/TS.35.341-354

[25] Vladareanu, L., Vladareanu, V., Yu, H., Mitroi, D., Ciocîrlan, A.C. (2019). Intelligent Control Interfaces Using Extenics Multidimensional Theory Applied on VIPRO Platforms for Developing the IT Industry 4.0 Concept. IFAC-PapersOnLine, 52(13): 922-927. http://dx.doi.org/10.1016/j.ifacol.2019.11.312.

\section{Authors}

Bo Yang, graduated from Chengdu Sport University with a master's degree, majoring in physical education and training. Yang Bo is now a teacher and lecturer in the Sports Teaching and Research Department of Heilongjiang Bayi Agricultural University, mainly engaged in the teaching of university PE courses, and concurrently serving as the head coach of the swimming team of Heilongjiang Bayi Agricultural University. During the 2008-2020 period as the head coach, the team members had won 2 gold medals, 1 silver medal and 4 bronze medals in the University Games of Heilongjiang Province. Yang Bo had published 12 provincial-level papers and 1 monograph, and had 1 patent for utility models.

Article submitted 2020-10-17. Resubmitted 2020-11-13. Final acceptance 2020-11-14. Final version published as submitted by the authors. 